\title{
A Bonesetter Medicinal Services Administrations to Enhance Individuals' Wellbeing in a Single Touch via Android Application
}

\author{
M. Parthiban, K.Naveena, D.Sathyapriya, P.Vanisri
}

\begin{abstract}
These days, advanced mobile phones have achieved each hand and each home. Thus, individuals are making utilization of the gainful portable applications to make their regular day to day existence less demanding. According to the insights, $27 \%$ of Indians kick the bucket without legitimate restorative help. Individuals have begun to concentrate on their wellbeing, yet at the same time they are looking for solid proposals. To decrease such multifaceted nature and memory required for each different application another application is required. The application, for example, incorporated across the board. In early proposed framework, it is accessible just to discover the ailment dependent on our indications. There are no further proposals about the supporting measure. The possibility of our undertaking is to give restorative help to individuals at their single touch. This application will give medicinal services administrations to enhance individuals' wellbeing. Utilizing this application individuals can get various advantages like data on blood accessibility, Body Mass Index number cruncher, issue discoverer, patient history etc.
\end{abstract}

Keywords:

\section{INTRODUCTION}

Medical services is an essential need of each person. Social insurance area is viewed as one of the biggest segment regarding both income and workforce business. The human services framework is principally furnished by the administration with practically no charge. Be that as it may, this accompanies numerous entanglements. The gigantic number of patients makes it troublesome for the administration emergency clinics to furnish them with a quality of human services. Accordingly, a large number of private emergency clinics are set up so as to meet the developing need of the majority for a quality social insurance. Yet, when one wishes to take administration from clinics, he/she first attempts to gather some data about that medical clinic. This data isn't just elusive yet in addition trouble to comprehend now and again. Particularly when individuals from rustic regions come to urban zones for better social insurance administration, they think that its exceptionally hard to pick an appropriate clinic. In addition, when looking at various medical clinics for discovering

Revised Manuscript Received on April 12, 2019.

M. Parthiban,Department of Computer Science and Engineering, V.S.B. Engineering College, Karur, Tamil Nadu, India-639111 (Email: parthim@mitindia.edu)

K.Naveena,Department of Computer Science and Engineering, V.S.B. Engineering College, Karur, Tamil Nadu, India-639111

D.Sathyapriya,Department of Computer Science and Engineering, V.S.B. Engineering College, Karur, Tamil Nadu, India-639111

P.Vanisri,Department of Computer Science and Engineering, V.S.B. Engineering College, Karur, Tamil Nadu, India-639111 better options, it represents a few complexities. The expense and quality for different administrations in an emergency clinic can be utilized as a measurement for correlation with different medical clinics which isn't constantly conceivable. With the current paper and written by hand for of patient records, there are a few outcomes, for example, (i) absence of openness of authentic wellbeing and medicinal insights concerning quiet, (ii) superfluous loss of time and cash for gathering or potentially examination of patient's wellbeing subtleties more than once (iii) absence of access the patients subtleties by other Healthcare establishments even with patients consent.

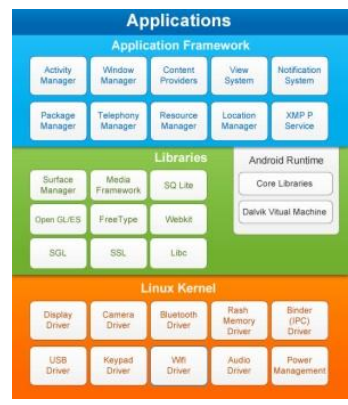

In this paper, a versatile application to make medicinal services progressively helpful for the majority is proposed. The explanation behind picking android stage is that the expense of android telephone is sensible and even destitute individuals can stand to have one. Moreover, android telephones are seen far reaching and all ages and class of individuals are utilizing it without problem. The application will give:

- Intelligent recommendation of medical clinics dependent on expense and Quality. Data about offices of medical clinics and their areas.

- Information about the specialist's chamber in a city

- Body Mass Record (BMI) number cruncher.

- Blood bank accessibility

The applications are additionally confirmed and approved by porting on a cell phone that runs android working framework. The proposed research discovers use in up and coming portable based purchaser applications for accomplishing expanded cost-adequacy, versatility and usability At first cell phones were created just for voice

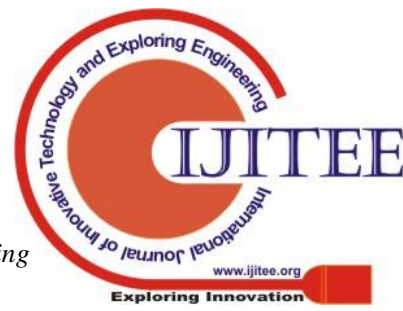




\section{A Bonesetter Medicinal Services Administrations To Enhance Individuals' Wellbeing In A Single Touch Via Android Application}

correspondence however at this point days the situation has changed, voice correspondence is only one part of a cell phone. Two such main considerations are internet browser and GPS administrations. Both of these functionalities are as of now actualized yet are just in the hands of makers not in the hands of clients in light of restrictive issues, the framework does not enable the client to get to the portable equipment straightforwardly.

\section{Android Architecture}

Android is a product stack it incorporates portable working framework, middleware and key candidates. Android engineering includes various types of layers: Linux piece, Libraries and android runtime, application system and applications. Each lower layer furnishes an interface with the upper layers utilizing epitome.

\section{Application Framework}

Android SDK gives you the Programming interface libraries and instruments for building and growing new applications on android working condition utilizing the java programming language. This methodology of building up the applications on android stage in java programming language utilizing the instruments and Programming interface libraries given by android SDK is called Android Application.

\section{EXPERIMENTAL RESULTS \& DISCUSSIONS}

In the Human services industry, usage of cloud innovation with the potential headway of Social insurance rolls out the sensational improvements. The advancement [1] of the appropriation of electronic wellbeing records (EHR) utilizing Distributed computing helps a great deal for the Human services network. There are a few applications in the market. There is a proposed a portable application which empowers patients to deal with their crucial measurements data and transmit the restorative data to human services suppliers. A portable application based framework in propounded in [17] to help specialists in observing patient prescription give an alert to the patient to expend the drug. However, this application produced for some patient. Another versatile application [10] of individual social insurance framework for patients with diabetes. An online tele social insurance framework proposed [11] in which was incorporated with the portable application for eating regimen individuals. What's more, online courses and information of eating routine are given in the framework. An incorporated [5] recommender structure for looking for specialists as per the patient's interest qualities, including their disease indications and their inclination is advanced in. A therapeutic application that stores the measurable database of patient. At that point created to [22] keep up to screen the patient and offer caution to devour drug. Another application, which gives BMI discoveries. At that point gave [1] the ailment side effect match and locate the patient disorder. Another incorporated application [3] that give taxi booking office to achieve specialists. In any case, this framework is utilized for little database and just the sickness indications coordinate are checked and used to discover illness for our disorder however no additional recommendations like solid sustenance, medical aid, and authority area, etc.

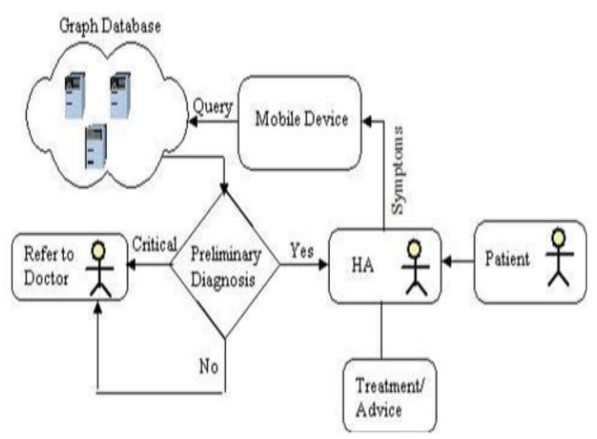

\section{PROPOSED SYSTEM}

The goal of our task is to give medicinal help to individuals at their single touch. According to the insights $70 \%$ of individuals endured without legitimate restorative rules. These days, individuals have begun to concentrate on their wellbeing, yet at the same time we are looking for solid recommendations. . The primary thought of our undertaking is to coordinate every one of the modules required for a social insurance into a solitary versatile application. This application comprises of five modules to give different data on blood accessibility.

\section{Login}

Initial one is login page. It gives enrollment to new client. Two fields are accessible to be specific client id and secret word. Every customer needs their information to be in a verified way. So it gives security as solid as could be expected under the circumstances. The client id and secret word is remarkable for every customer.

\section{Personal Details}

In next page client ought to enter their very own data, for example, DOB, blood gathering, address, portable number, etc. The client can likewise alter their data in further stages. This leads a way to module page.

\section{Module Page}

\section{a) Body Mass Index [BMI]}

The BMI is the initial step for a person to think about their wellbeing. At the point when this module is clicked, two fields show up in particular stature and weight. On the off chance that outcome catch is clicked, BMI esteem is determined and appeared to the client. On the off chance that the BMI esteem is ordinary, gratefulness is remarked through notice. On the off chance that it is strange, at that point some therapeutic tips will be given to keep their BMI in a reasonable way.

\section{b) Problem finder}

\section{i) Symptom-Disease Matching}

The learning base Illness Manifestation database is put away in cloud which will be open from portable. At first essential indications are stacked into versatile de-bad habit from database. 
- User chooses essential manifestations and after this determination, indication of the side effects is stacked into the cell phone.

- After choosing essential manifestations and indications of the side effects, the threat signs (the peril signs are the clinical conditions which are require more consideration for a specific sickness) are put away independently.

- This process proceeds until there is have to check whether any more indications coordinate with client or not.

- Finally when no additionally checking is required, demand will be sent to database to give treatment plan against identified illnesses.

\section{ii) Solution Provider}

- Then recognized ailment/sicknesses, manifestations (chosen by client) and treatment plan will be shown with the end goal that client can get primer treatment.

- If any side effects are found as perilous or no infection is identified, client will be alluded to the specialist.

\section{iii) Specialist Guidance}

In this application there is a stunning segment called expert proposal. Here a comprehensive recommendation of emergency offices and specialists can be picked up. It presents two portrayals of recommendation to the client. The major choice sorts the emergency offices by the work environments they oblige perspective, the measure of full time specialists, number of intensity aces, number of development theatres, number of lodges and client rating from online objectives, for example, google.com. For each helpful issue, the subtleties of the ace will be given. The profile of the pro unite name, space name, area, and so forth., By this office, individuals can discover unequivocal experts of each space and approach them for getting help from ailments. To help discover emergency focus an area, the application gives a choice to getting remedial office zone. Clients can without a lot of a stretch discover district of helpful office with a solitary tap. The framework will open up the Google map application and etching the office's district.

\section{c) Blood Availability}

Our next module is 'blood accessibility', which is basic for the human life. In light of the patient's present area, all the close-by blood donation centre focuses are appeared. Utilizing Google map the present area of the patient is followed and blood donation centres with refreshed blood accessibility are shown.

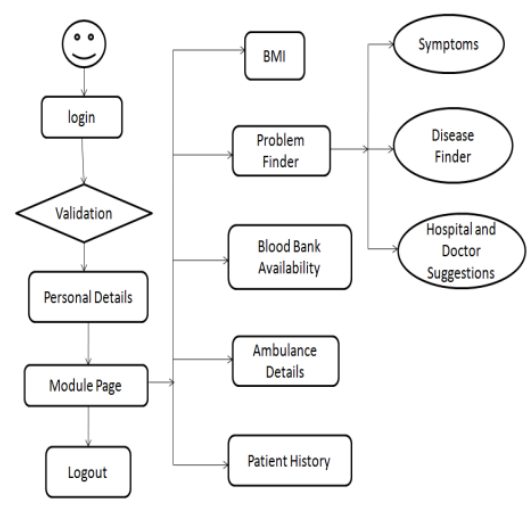

Register $\log$ in

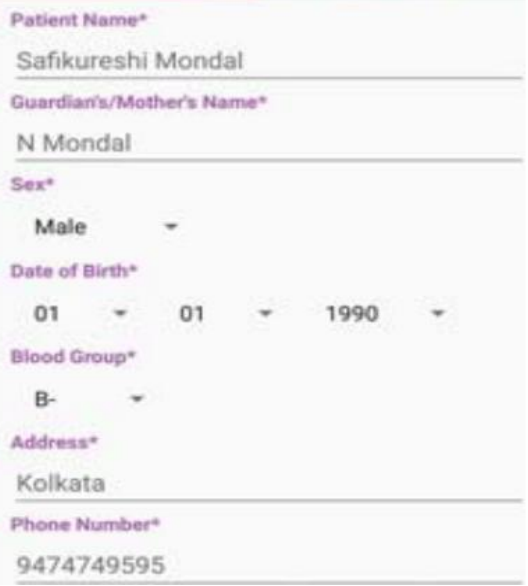

Our next module is 'blood accessibility', which is basic for the human life. In light of the patient's present area, all the close-by blood donation centre focuses are appeared. Utilizing Google map the present area of the patient is followed and blood donation centres with refreshed blood accessibility are shown.

\section{d) Ambulance service}

\begin{tabular}{|c|c|}
\hline Details & Edit \\
\hline Patient ID & 12 \\
\hline Patient Name* & Safikureshi Mondal \\
\hline $\begin{array}{l}\text { Guardiamis/Mother's } \\
\text { Name* }\end{array}$ & Ne Mondal \\
\hline Sext & Male \\
\hline Date of Eirth" & $1 / 7 / 1990$ \\
\hline Elood Group" & a- \\
\hline Address: & Kolkata \\
\hline Phone Number" & 9474749595 \\
\hline Malil Id & msaf.eseggmall com \\
\hline PROCEED & \\
\hline
\end{tabular}

This module is utilized to give insights concerning emergency vehicle benefits in adjacent territories according to the client area given in their own subtleties page. It additionally alludes area of those administrations by coordinating into Google map. This may assist the client with accessing the administration for any crisis.

\section{e) Patient History}




$\leftarrow$ Other signs $\quad$ Symptoms
$\square$ Vomiting blood
$\square$ Yellow Urine
$\square$ Darker Urine
$\square$ Facing trouble to see at night
$\square$ Vomiting tendency
$\square$ Brown Urine

It shows the history of the patients like patient medicine intake, early surgery etc.

\section{CONCLUSION}

The proposed Android as a full, open and free cell phone stage, with its amazing capacity and great client experience, quickly formed into the most well known portable working framework. The exploration work displayed in this includes new administration based structure approach for actualizing two of the famous customer applications on Android framework. One of them is utility look places application for customer. In this paper, "A BONESETTER IN A Solitary TOUCH through android application" we built up a coordinated android application with the mean to propose individuals in their human services issues and help them to keep up a solid and calm life. Consequently we intend to construct a sound society by helping individuals through Innovation.

Presently, this application demonstrates the static rundown of specialists accessible in the specific medical clinic. This application can be upgraded to give continuous data about the specialist present specifically time in the particular clinic and furthermore can be improved to include modules to help client from worry by giving recordings and progressively solid proposals.

\section{REFERENCES}

1. MoRe-care: Mobile-assisted remte healthcare service deliver(2018)- Rubel Das, Safikureshi Mondal, Nandini Mukherjee.

2. Healthcare-As-A-Service-Hospit one- A Cloud Based Healthcare System(2015)S.K.Senthil Kumar, P.Balasubramanie.

3. Optimization in Mobile Cloud Computing for Cloud Based Health Application Gurudatt Kulkarni;Rupali Shelke;Pooja Bhore Niraj Patil;Vishakha Kulkarni;Sangita Mohite.

4. A Smart phone based Application to improve the Healthcare System of Bangladesh(2016)- Ahmed Imteaj and Muhammad Kamrul Hossain.

5. L. Atack L and J. Maher, "Emergency medical and health providers\&\#39; perceptions of key issues in prehospital patient safety," Prehosp Emerg Care, vol.14, no.1,pp.95102,March 2010.

6. M. Fourny, AS. Lucas, L. Belle, G. Debaty, P. Casez, H. Bouvaist, P.François, G. Vanzetto and J. Labarère, "Inappropriate dispatcher decision for emergency medical service users with acute myocardial infarction", Am J Emerg Med., vol.29, no.1, pp.37-42, Jan. 2011.

7. Akash Borate, Ketan Bhapkar, Darpan Sharma. \&quot;Android Based Fuzzy Inference System to Control the
Fan Speed\&quot;. Journal of Harmonized Research in Engineering 2(1), pg 69-74, 2014.

8. Google Play https://play.google.com/store/apps/category/MEDICAL Accessed on April 25, 2015.

9. Amit M. Farkade, Sneha R. Kaware. \&quot;The Android- A Widely Growing Mobile Operating System With its Mobile based Applications\&quot;. International Journal of Computer Science and Mobile Applications\&quot;, Vol.3 Issue. 1, pg. 39-45, January 2015.

10. F.Zhou,"Mobile personal healthcare system for patient with diabetes",Graduate Thesis and Dissertions, 2011.

11. Sanjay AP, Mani S, and Zambrano J, "A survey of the state of cloud computing in healthcare", Network and Communication Technologies 1, no. 2: p12, 2012.

12. Oberdan RC, Koch FL, Westphall CB, Werner J, Fracalossi A, and Salvador GS. "A cloud computing solution for patient's data collection in health care institutions." In eHealth, Telemedicine, and Social Medicine, ETELEMED'10. Second International Conference on, pp.95-99. IEEE, 2010.

13. Yan $\mathrm{H}$ and Guohua Bai. "A systematic literature review of cloud computing in eHealth." arXiv preprint arXiv: 1412.2494, 2014.

14. Chatman, C., "How cloud computing is changing the face of health care information technology", Journal of Health Care Compliance, 12(3), 37-70, 2010.

15. Kuo, Alex Mu-Hsing. "Opportunities and challenges of cloud computing to improve health care services." Journal of medical Internet research 13, no. 3, 2011.

16. Mobile Healthcare Opportunities, Monitoring Applications \& mHealth Strategies 2010-2014. Juniper Research. April 13, 2010.

17. "Mobile Applications for the Health Sector",Christine Zhenwei Qiang, Masatake Yamamichi*, Vicky Hausman and Daniel Altman, Bank December 2011.

18. "Remote Patient MonitoringWithin a Future 5G Infrastructure",Vladimir Oleshchuk · Rune Fensli Springer Science+Business Media, LLC. 2010.

19. H.Jiang, W. Xu, "How to find your appropriate doctor," in Proceedings of Computational Intelligence in Healthcare and e-health (CICARE), pp. 154-158, 9-12 Dec. 2014.

20. Sekar, J. B. Liu, "Location Based Mobile Apps Development On Android Platform," in Proceedings of 9th Conference on Industrial Electronics and Applications (ICIEA), 2014.

21. A.Carpio, J. Kim, R. Hoda, "MedTouch: Towards the Development of Smartphone-basedSoftware Solutions for Mobile Health Care," in Proceedings of Australasian SoftwareEngineering Conference, 4-7 June 2013.

22. Z. A. Habash, W. Hussain, W. Ishak, and M. H. Omar, "Android-Based Application to Assist Doctor with Alzheimer's Patient," International Conference on Computing and Informatics (ICOCI), 28-30 August, 2013.

23. K. Hung, Y.T. Zhang, \&quot;Implementation of a WAPBased Telemedicine System for Patient Monitoring\&quot;, IEEE TransactionsOn Information Technology In Biomedicine, vol. 7, no. 2, June 2003.

24. R.A. Nimbalkar, R.A. Fadnavis, \&quot;Domain Specific Search Of Nearest Hospital And Healthcare Management System\&quot;, Proceedings of Recent Advances in Engineering and Computational Sciences (RACECS), pp. 1-5, 06-08 March, 2014.

25. Vikas Kulshreshtha, Sharad Maheshwari, \&quot;Benefits of Management Information System in Blood Bank\&quot; International Journal of Engineering and Science, vol. 1, no. 12, pp. 05-07, 2012. 